\title{
Optimum Sizing of Photovoltaic and Energy Storage Systems for Powering Green Base Stations in Cellular Networks
}

\author{
Mahshid Javidsharifi ${ }^{1, *}$, Hamoun Pourroshanfekr ${ }^{2}$, Tamas Kerekes ${ }^{1} \mathbb{D}$, Dezso Sera ${ }^{3}$, , Sergiu Spataru ${ }^{4} \mathbb{D}$ \\ and Josep M. Guerrero ${ }^{1}$ (D) \\ 1 Department of Energy Technology, Aalborg University, 9220 Aalborg, Denmark; tak@et.aau.dk (T.K.); \\ joz@et.aau.dk (J.M.G.) \\ 2 Faculty of Engineering, Lund University, 22100 Lund, Sweden; Pr.roshanfekr@gmail.com \\ 3 Faculty of Science and Engineering, Queensland University of Technology, Brisbane, QLD 4000, Australia; \\ dezso.sera@qut.edu.au \\ 4 Department of Photonics Engineering, Technical University of Denmark, 4000 Roskilde, Denmark; \\ sersp@fotonik.dtu.dk \\ * Correspondence: mja@et.aau.dk; Tel.: +45-22349975
}

Citation: Javidsharifi, M.;

Pourroshanfekr, H.; Kerekes, T.; Sera,

D.; Spataru, S.; Guerrero, J.M.

Optimum Sizing of Photovoltaic and Energy Storage Systems for Powering Green Base Stations in Cellular

Networks. Energies 2021, 14, 1895.

https://doi.org/10.3390/en14071895

Academic Editor: Luigi Fortuna

Received: 26 February 2021

Accepted: 23 March 2021

Published: 29 March 2021

Publisher's Note: MDPI stays neutral with regard to jurisdictional claims in published maps and institutional affiliations.

Copyright: (c) 2021 by the authors. Licensee MDPI, Basel, Switzerland. This article is an open access article distributed under the terms and conditions of the Creative Commons Attribution (CC BY) license (https:/ / creativecommons.org/licenses/by/ $4.0 /)$.

\begin{abstract}
Satisfying the mobile traffic demand in next generation cellular networks increases the cost of energy supply. Renewable energy sources are a promising solution to power base stations in a self-sufficient and cost-effective manner. This paper presents an optimal method for designing a photovoltaic $(P V)$-battery system to supply base stations in cellular networks. A systematic approach is proposed for determining the power rating of the photovoltaic generator and battery capacity from a technical and economical point of view in order to minimize investment cost as well as operational expenditure, while the power autonomy of the $P V$-battery system is maximized in a multi-objective optimization framework. The proposed method is applied to optimally size a photovoltaic-battery system for three cases with different availability of solar power to investigate the effect of environmental conditions. Problem-solving using the proposed approach leads to a set of solutions at different costs versus different levels of power autonomy. According to the importance of each criterion and the preference of decision-makers, one of the achieved solutions can be selected for the implementation of the photovoltaic-battery system to supply base stations in cellular networks.
\end{abstract}

Keywords: photovoltaic system; battery storage device; base stations; cellular networks

\section{Introduction}

In recent years, the energy consumption of information and communication technology (ICT) has become an economic issue for operators and a major challenge for sustainable development [1]. The energy consumption of the ICT industry accounts for approximately $3 \%$ of global annual energy consumption and is growing at an annual rate of 15-20\% [1] The carbon footprint from ICT is furthermore predicted to increase $7.3 \%$ annually and exceed $14 \%$ of the global footprint by 2040 . The need to bring next generation cellular telecommunication network services to areas that do not have access to a reliable power grid results in a variety of objective challenges for telecom providers, government agencies, and researchers. Solar-powered cellular telecommunication networks can be particularly significant for regions that have poor grid connectivity while being rich in solar resources [2]. Using solar energy for supplying cellular telecommunication networks not only reduces the carbon emission, but also lowers operational cost as compared to powering from the grid or conventional sources of energy [3].

Deployment of renewable sources, such as solar photovoltaic $(P V)$ panels, is currently increasing in order to meet the needs of growing energy demand and to mitigate the impact of fossil pollutants on the environment and guarantee socio-economic benefits for sustainable development [4]. Despite their advantages, the intermittent nature of 
most of the renewable sources is still a challenge that can be resolved by hybridization. A renewable-hybrid energy system (RHES) combines renewable energy sources (RESs), energy storage (ES) devices, such as batteries, and the electrical grid to supply the base stations [5].

Research has been done concerning the possibility of powering a base station in a telecommunication network with solar $P V$ panels and battery for ES such that the base station could operate even when the $P V$ panel was not producing energy. In [5], the authors studied cellular access networks, which solely relied on renewable energy, while in [6], an exchange link between the $P V$ panels and the main grid exists. Authors in [7] suggested a traffic-aware renewable energy assisted base station cooperation. The focus of some papers, [8-11], was on the overview of sustainable and green mobile network deployment, while some others, [12,13], focused on modeling the behavior of renewable-based base stations in order to dimension the system components correctly by understanding the system characteristics. In [12-14], a study was presented about the Markovian models to compute the possibility of base station interruption in a solar-powered cellular network. In [12], two Markov chain models based on solar irradiation data, respectively in two and three successive days were considered. The objective of [12] was to expose the influence of correlation in weather conditions. Furthermore, only the influence of different battery sizes on the operation of the system was studied. Authors in [13] considered a similar model as in [12], while they investigated the impact of three different types of quantizationweather characteristics, duration of time steps, and size of the battery to analyze the performance of renewable energy-based power supply for cellular networks. In [14], a discrete-time Markov procedure for modeling the battery state of charge (SOC) was proposed which could be applied for assessing the impact of system parameters on the base station interruption probability.

Optimal energy management of green next generation telecommunication networks is another aspect which was investigated in [2,15-30]. The "energy consumption-based and user joint allocation" approach together with "the energy cost-based and user joint allocation" method were presented in [2]. After converting the two multi-objective optimization problems into two convex optimization problems, the convex optimization toolbox in MATLAB (MathWorks corporate, Natick, MA, USA) was used to solve the optimal allocation strategies. The focus in [15] was on decreasing the "on-grid energy consumption in Heterogeneous telecommunication Networks (HetNets)" supplied with hybrid power sources while analyzing the short- and long-term energy efficiency problem. In [16], a user association approach for improving the behavior of hybrid energy-based HetNets was proposed. Authors in [17] considered an online energy management framework for mobile networks, including both on- and off-grid base stations. Reference [18] investigated four techniques, including "the base station sleeping strategy," "the optimized energy procurement from the smart grid," "the base station energy sharing", and "the green networking collaboration between competitive mobile operators".

In order to provide environmental and economic benefits for wireless operators, these techniques could be exploited separately or together. Optimization of $P V$ panel azimuth angle was considered in $[19,20]$. The purpose was to attain an acceptable match between the daily energy generation and consumption profiles. In [19], the considered system was off-grid and consisted of one $P V$ cell while in [20], several $P V$ cells were used for powering one on-grid base station and the objective was to optimize the azimuth angles of $N P V$ cells to draw less energy per day from the main grid. Reference [21] presented an analytical method to find a suitable combination of $P V$ panels and batteries to power base stations to reduce the required capital expenditure (CAPEX). In [22], the feasibility of solar $P V$ power generation for cellular networks from technical, economic, and environmental aspects was investigated from a mobile network operator point of view. The power rating of the $P V$ system was determined based on total cost including CAPEX and operational expenditure (OPEX). The effects of quantization in the three parameters of the model including time slot in horizon of study, weather, and ES capacity in dimensioning of the 
power system of $P V$-powered off-grid base stations were examined in [23]. The target of [24] was to minimize the installation costs for an unmanned aerial vehicle (UAV)-based cellular network, considering the constraints of UAV's coverage, solar panel energy consumption, levels of the batteries, and the deployment of the optical ring for connecting the installed sites. In [25], in order to prepare a reliable emission-free and economic power supply, optimal sizing of a hybrid renewable energy system based on a discrete multi-objective grey wolf algorithm was applied in off-grid rural base stations. In [26], a low complexity approach based on a convex optimization framework was proposed for dimensioning $P V$ battery systems in a stand-alone base station. The techno-economic feasibility of renewable energy-based off-grid cellular base stations was studied in [27]. The stochastic nature of renewable energy sources in addition to the load traffic for distant regions in Bangladesh was also considered. Authors in [28] investigated the layout of green mobile networks (using renewable energies) by setting up an intelligent energy management that facilitates the off-grid operation of base stations. In [29], the validity of some power supply solutions such as "standalone $P V$ ", "hybrid $P V$-wind turbine," "hybrid $P V$-diesel generator", and "hybrid $P V$-electric grid" was examined to supply the long-term evolution (LTE) base stations associated with technical, economic, and environmental prospects in Bangladesh. In [30], an energy management strategy was suggested in order to improve the energy efficiency of, and to reduce fuel consumption in, off-grid cellular networks supplied with a hybrid $P V$-diesel generator system.

Regarding the scope of these studies, it is observed that almost all of them focused on the $P V$-battery systems, while none of them was dedicated to an accurate model for available $P V$ output power generation estimation. Moreover, in the $P V$-battery system case, the $S O C$ limits as well as battery operation cost were not considered. Current models of power management in these systems do not take the ambient temperature effect, battery degradation, or feed-in tariff into account. Therefore, this paper will start by defining realistic scenarios used in combination with models of power generation and storage devices to evaluate the power generation capability and ES capacity of $P V$-battery powered base stations. Subsequently, an optimization framework will be developed and formulated for determining the power rating of $P V$ panels and battery capacity from a technical and economical point of view in order to minimize CAPEX as well as OPEX while the power autonomy of the $P V$-battery system is maximized.

\section{System Structure}

Figure 1 illustrates the energy flow within different elements of a solar-powered next generation telecommunication network that consists of a macro base station (MBS) and two small base stations (SBS). The red arrows represent the energy flows, whereas the blackdashed arrows represent the communication links. Each base station is equipped with a $P V$ battery system. The energy management system (EMS) unit as a central controller collects information regarding power consumption, generation, and ES state, and sends commands to the dispatchable units [3]. The determination of the power rating of the $P V$ system and battery capacity in $P V$-battery equipped base stations can be tackled by establishing an optimization framework which considers the amount of available power produced by installed $P V$ panels and the profile of power consumed by the base stations (BSs). 


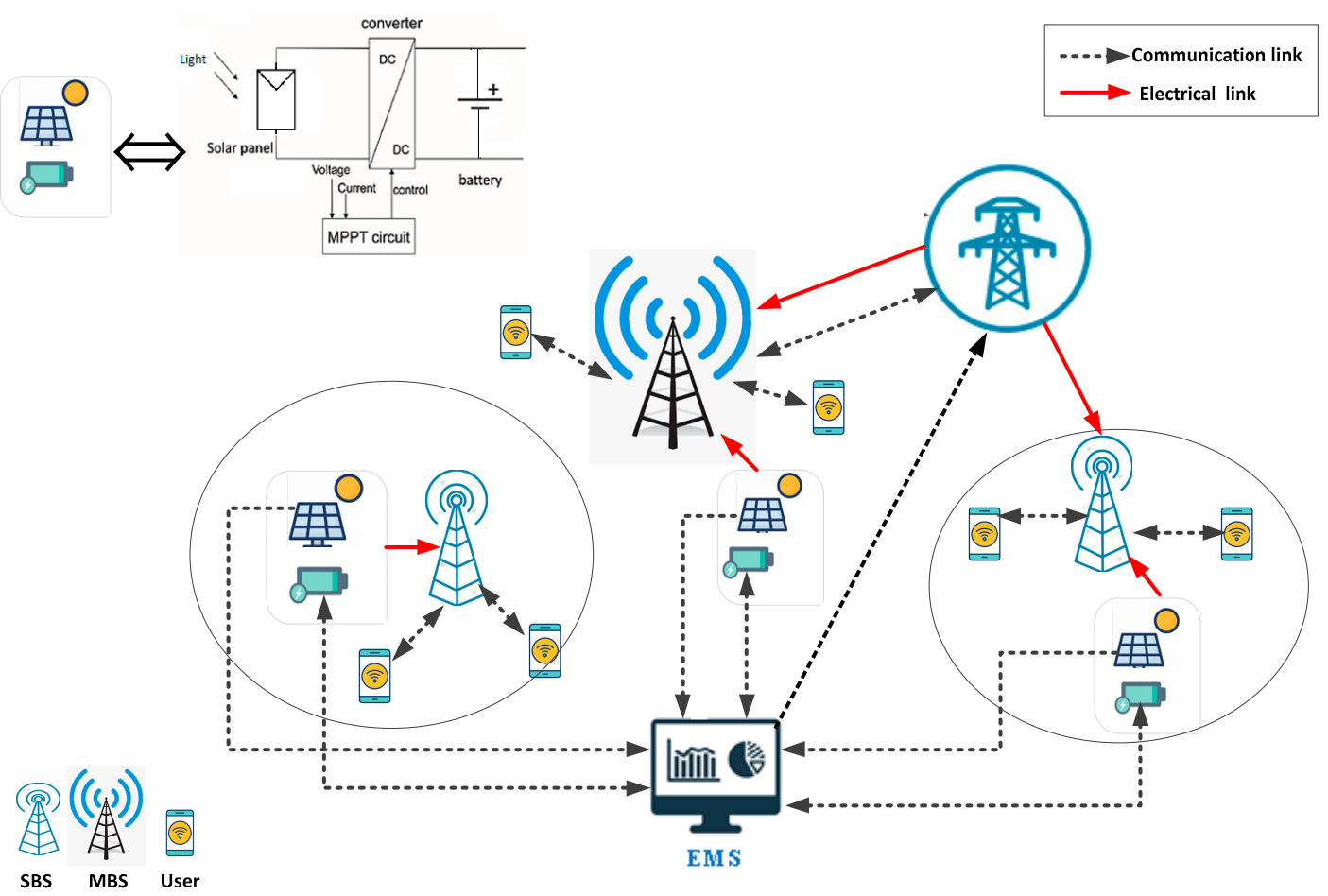

Figure 1. The configuration of next generation cellular telecommunication networks.

\subsection{PV Generation Modeling}

The aim of this section is to select a mathematical model for $P V$ power generation. Several models to estimate the output power of a $P V$ system have been proposed in the literature [19]. The solar power generation in different geographical locations depends on a variety of parameters, including solar irradiance and installation angles of $P V$ panels, as well as cell and ambient temperatures [31]. The studied models of solar-powered base stations were investigated while considering some of the above-mentioned parameters. The considered model in this paper is based on the one proposed in [19], while the model is enhanced to include cell temperature effects.

From the photovoltaic geographical information system (PVGIS) database [32], the direct normal irradiance $D N I^{t}$, the diffuse horizontal irradiance $D H I^{t}$, and the global horizontal irradiance $G H I^{t}$ in three different case studies of Malaga, Aalborg, and Boujdour are obtained for each hour.

When installing a $P V$ system, the location optimal tilt and azimuth angles, $\gamma$ and $\theta$, can guarantee the maximum achievable solar power. A detailed research on installation angles of a $P V$ panel was presented in [19].

The generated $P V$ power can be modeled as follows:

$$
P_{P V}^{t}=\frac{I^{t}(\theta, \gamma) \times P_{P V}^{P e a k}}{1000}
$$

where $P_{P V}^{P e a k}$ is the $P V$ system rated power. $I^{t}(\theta, \gamma)$ is the received solar irradiance by the $P V$ system which can be calculated as follows:

$$
I^{t}(\theta, \gamma)=I_{b}^{t}(\theta, \gamma)+I_{d}^{t}(\theta, \gamma)+I_{g}^{t}(\gamma)
$$

where $I_{b}^{t}(\theta, \gamma), I_{d}^{t}(\theta, \gamma), I_{g}^{t}(\gamma)$ are the direct-beam, sky-diffuse, and ground-reflected components, respectively.

$I_{b}^{t}(\theta, \gamma)$ (the direct-beam component) is defined as follows:

$$
I_{b}^{t}(\theta, \gamma)=D N I^{t} \times \operatorname{Max}\left(0, \cos \left(A O I_{\theta}^{t}\right)\right)
$$


where $A O I_{\theta}^{t}$ is the angle of incidence at $t$ and can be calculated in [19] as the following:

$$
\begin{aligned}
& \cos \left(A O I_{\theta}^{t}\right)=+\sin \left(\delta_{d}\right) \sin (\text { lat }) \cos (\gamma) \\
&+\cos \left(\delta_{d}\right) \cos (\text { lat }) \cos (\gamma) \cos \left(\omega_{t}\right) \\
&+\cos \left(\delta_{d}\right) \sin (\gamma) \sin \left(\omega_{t}\right) \sin (\theta) \\
&-\sin \left(\delta_{d}\right) \cos (\text { lat }) \sin (\gamma) \cos (\theta) \\
&+\cos \left(\delta_{d}\right) \sin (\text { lat }) \sin (\gamma) \cos \left(\omega_{t}\right) \cos (\theta) \\
&=a_{t}+b_{t} \sin (\theta)+c_{t} \cos (\theta)
\end{aligned}
$$

with

$$
\begin{gathered}
a_{t}=+\sin \left(\delta_{d}\right) \sin (\text { lat }) \cos (\gamma) \\
+\cos \left(\delta_{d}\right) \cos (\text { lat }) \cos (\gamma) \cos \left(\omega_{t}\right) \\
b_{t}=+\cos \left(\delta_{d}\right) \sin (\gamma) \sin \left(\omega_{t}\right) \\
c_{t}=-\sin \left(\delta_{d}\right) \cos (\text { lat }) \sin (\gamma) \\
+\cos \left(\delta_{d}\right) \sin (\text { lat }) \sin (\gamma) \cos \left(\omega_{t}\right)
\end{gathered}
$$

where the latitude of the installation site is demonstrated by lat, $\delta_{d}$ is the declination angle, and $\omega_{t}$ is the hour angle at $t$ [19], which are respectively calculated as follows:

$$
\delta_{d}=23.45^{\circ} \times \sin \left(\frac{360}{365}(d+284)\right) \text { and } \omega_{t}=15(\text { AST }-12 \text { hour }) .
$$

where $d$ is the day of the year and AST is the apparent (true) solar time [32], which is calculated as follows:

$$
A S T=L S T+E o T+\left(4 \frac{\min }{\mathrm{deg}}\right)[(L S M T-L O D)]
$$

where $L S T$ is the local standard time, $L O D$ is the longitude, $L S M T$ is the local standard meridian time, and EoT is the equation of time [33], which are given, respectively, as follows:

$$
\begin{gathered}
\text { LSMT }=15^{\circ} \times \text { Time zone in GMT } \\
\text { EoT }=9.87 \sin (2 B)-7.53 \cos (B)-1.5 \sin (B)
\end{gathered}
$$

where $B$ is a factor calculated as follows:

$$
B=\frac{360^{\circ}}{365}(d-81)
$$

$I_{d}^{t}(\theta, \gamma)$ (the sky-diffuse component) is defined as the following:

$$
\begin{gathered}
I_{d}^{t}(\theta, \gamma)=D H I^{t}\left\{A_{t} \frac{\max \left(0, \cos \left(A O I_{\theta}^{t}\right)\right)}{\cos \left(\zeta_{t}\right)}+\right. \\
\left.\left(1-A_{t}\right) \frac{1+\cos (\gamma)}{2}\left(1+\sqrt{\frac{D N I^{t} \cdot \cos \left(\zeta_{t}\right)}{G H I^{t}} \sin ^{3}\left(\frac{\gamma}{2}\right)}\right)\right\}
\end{gathered}
$$

where $A_{t}$ is the anisotropy index and $\zeta_{t}$ is the solar zenith angle, which are calculated as follows:

$$
\cos \left(\zeta_{t}\right)=\sin (\text { lat }) \sin \left(\delta_{d}\right)+\cos (\text { lat }) \cos \left(\delta_{d}\right) \cos \left(\omega_{t}\right) A_{t}=\frac{D N I^{t}}{E_{d}}
$$

where $E_{d}$, the extraterrestrial radiation, is calculated as follows:

$$
E_{d}=E_{c o n} \cdot\left(\frac{\bar{r}}{r_{d}}\right)^{2}=E_{c o n} \cdot\left(1+0.033 \cos \left(\frac{360 \cdot d}{365}\right)\right)
$$


$I_{g}^{t}(\gamma)$ (the ground-reflected component) is defined as follows:

$$
I_{g}^{t}(\gamma)=G H I^{t} \times \alpha \times \frac{1-\cos (\gamma)}{2}
$$

where $\alpha \in[0,1]$ is the albedo of the ground [19].

In order to make the model more realistic, the panel temperature should be added to the model. The cell temperature is dependent on the ambient temperature and the total irradiation on the $P V$ system is based on the nominal operating cell temperature (NOCT), which is considered $45^{\circ}$ [34].

$$
T_{C}^{t}=T_{a}^{t}+\left[\frac{N O C T-20}{800}\right] \times I^{t}(\theta, \gamma)
$$

where $T_{a}^{t}$ is the ambient temperature. Accordingly, the generated $P V$ power of (1) is modified as:

$$
P_{P V}^{t}=\frac{I^{t}(\theta, \gamma) \times P_{P V}^{P e a k} \times\left(1+d p\left(T_{C}^{t}-25\right)\right)}{1000}
$$

where $d p\left(\% /{ }^{\circ} \mathrm{C}\right)$ is the temperature coefficient which is considered -0.4 in this paper.

In order to validate the built model, the estimated output power based on the presented model using the irradiation and temperature data from the Aalborg University (AAU) site as well as the PVGIS [32] are compared with the measured output power of the installed $P V$ system in the AAU for 23 April 2009 and the results are shown in Figure 2.

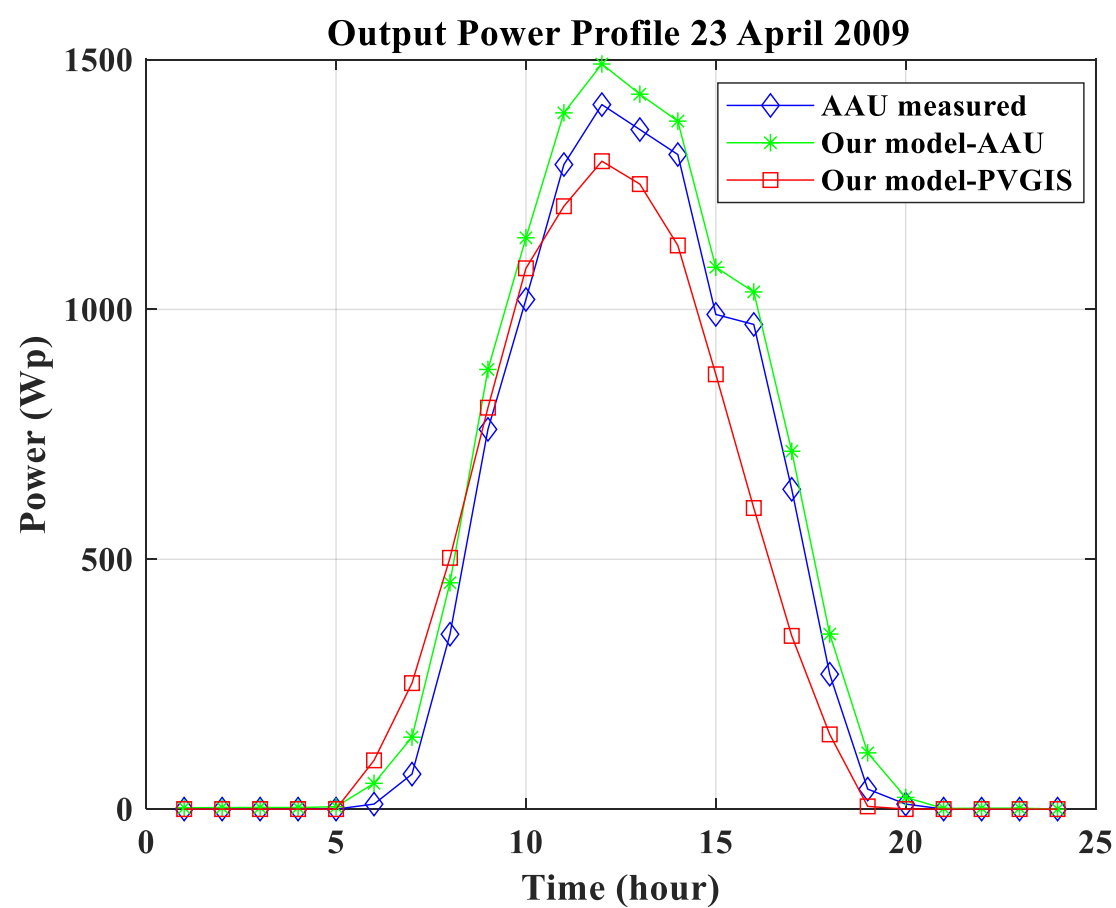

Figure 2. Comparison of the measured output power (Aalborg University (AAU) measured) of the installed photovoltaic $(P V)$ system in the AAU with the estimated output power based on the presented model using the irradiation and temperature data from the AAU site (Our model-AAU) as well as the photovoltaic geographical information system (PVGIS) (Our model-PVGIS).

\subsection{Energy Storage Modeling}

In order to deal with the intermittent nature of RESs systems that combine these sources and ES devices, some suggestions were made in the literature. A review of battery energy storage modeling was presented in [35].

In this paper, it is assumed that the solar energy is first used to power the base station, and the excess energy is stored in the battery (if not fully charged). During the periods 
when no solar energy is being generated, e.g., during the night or in cloudy weather, or if the $P V$ production is not sufficient to satisfy the base station demand, the stored energy can be used. In case the battery fully discharges, the required power can be drawn from the grid, if applicable [3] (Figure 1).

For considering the limitation on the battery charge and discharge rates along with limits on the state of charge (SOC), the following equation and constraints should be satisfied [36]:

$$
\begin{gathered}
S O C_{\text {Batt,min }} \leq S O C_{\text {Batt }}^{t} \leq S O C_{\text {Batt,Max }} \\
S O C_{\text {Batt }}^{t}=S O C_{\text {Batt }}^{t-1}+\frac{\eta_{C h} P_{C h}^{t} \cdot \Delta t}{B_{c a p}}+\frac{1}{\eta_{D c h} \cdot B_{c a p}} P_{D c h}^{t} \cdot \Delta t \\
P_{C h, \text { min }} \leq P_{C h}^{t} \leq P_{C h, \text { Max }} \\
P_{D c h, \text { min }} \leq P_{D c h}^{t} \leq P_{D c h, M a x}
\end{gathered}
$$

where $S O C_{B a t t, \text { min }}$ and $S O C_{B a t t, M a x}$ are, respectively, the minimum and maximum $S O C$ of the battery, $S O C_{B a t t}^{t}$ is the battery $S O C$ at time $t, P_{C h}^{t}$ and $P_{D c h}^{t}$ are the battery charge and discharge rates at time $t, B_{c a p}$ is the battery capacity, $\eta_{C h}$ and $\eta_{D c h}$ are, respectively, the battery charge and discharge efficiencies, and $\Delta t$ is the time slot. $P_{C h \text {, min }}$ and $P_{D c h \text {,min }}$ are the battery minimum charge and discharge rates, and $P_{C h, M a x}$ and $P_{D c h, M a x}$ are the battery maximum charge and discharge rates, respectively.

\section{Problem Formulation}

The main advantages of energy harvesting from $P V$-battery systems in telecommunication networks are: (i) selling the excess power of the $P V$-battery system to the main grid, and (ii) increasing the power autonomy factor, which leads to increasing the reliability of the system due to the reduction of dependency on the main grid [37].

This section is devoted to the presentation of the considered objective functions including the minimization of the total cost and the maximization of the power autonomy factor of the $P V$-battery system.

\subsection{Minimization of the Total Cost}

The first objective $\left(O F_{1}\right)$ is to minimize the total financial costs of the $P V$-battery power system, including CAPEX and OPEX, from the mobile network operator (MNO) point of view:

$$
\begin{aligned}
& \quad \text { OF }_{1}=\min (\text { TotalCost }) \\
& \text { TotalCost }=\text { CAPEX }+ \text { OPEX }= \\
& B_{\text {cap }} \cdot \text { Cost }_{\text {Batt }}+P_{P V}^{\text {peak }} \cdot \operatorname{Cost}_{P V}+A_{P V} \cdot \text { Cost }_{\text {Rent }} \\
& +\sum_{t=1}^{H}\left(\text { OPEX }_{\text {Batt }}^{t}+P_{\text {grid }}^{t} \cdot \operatorname{Pr}^{t}\right)
\end{aligned}
$$

where $\operatorname{Cost}_{\text {Batt }}$ is the cost of battery in $\$$ and $A_{P V}$ is the installation area of the $P V$ system in $\mathrm{m}^{2}$. Cost $t_{P V}$ is the cost of $P V$ panels in $\$ / \mathrm{kW}$, Cost $t_{\text {Rent }}$ is the rental cost of installation area in $\$ / \mathrm{m}^{2}, P_{\text {grid }}^{t}$ is the power of the main grid in $\mathrm{kW}$, and $\operatorname{Pr}^{t}$ is the electricity price in $\$ / \mathrm{kWh}$. $H$ is the horizon of study, which equals $D \times T$ (number of days of the year multiplied by the number of hours in a day), and OPEX $X_{\text {Batt }}^{t}$ is the battery operational cost, including the SOC-related $\left(\right.$ Cost $\left._{S O C}\right)$ as well as DoD-related $\left(\operatorname{Cost}_{D o D}\right)$ costs [38]:

$$
\begin{gathered}
\text { OPEX } X_{\text {Batt }}^{t}=\sum_{t=1}^{H} \operatorname{Cost}_{S O C}^{t}+\sum_{t=1}^{H} \operatorname{Cost}_{\text {DoD }}^{t} \\
\operatorname{Cost}_{\text {SOC }}^{t}=\operatorname{Cost}_{\text {Batt }} \cdot \frac{\text { LBDS } \cdot S O C_{\text {Batt }}^{t}-\text { LBDI }}{8760 \cdot C F_{\text {Max }} \cdot \text { Batt }_{\text {life }}}
\end{gathered}
$$




$$
\begin{gathered}
\operatorname{Cost}_{\text {DoD }}^{t}=\frac{\operatorname{Cost}_{\text {Batt }} \cdot B_{\text {cap }}+\operatorname{Cost}_{\text {labor }}}{\text { Batt }_{\text {life }} \cdot D_{0} D_{\text {Batt }}^{t} \cdot B_{\text {cap }}} \cdot\left(P_{\text {Dch }}^{t}\right) \\
\operatorname{DoD}_{\text {Batt }}^{t}=1-\operatorname{SOC}_{\text {Batt }}^{t}
\end{gathered}
$$

where $L B D S$ is the linear battery degradation cost-slope parameter, $L B D I$ is the linear battery degradation cost-intercept, $C F_{M a x}$ is capacity fade at end of life, and Cost labor is the labor cost for battery replacement, the values of which are derived from [38].

\subsection{Maximization of the Power Autonomy Factor}

Prevention of greenhouse gas emissions is another major goal of $P V$ system implementation in different applications. Accordingly, if the share of the main grid to supply the base stations decreases, the amount of carbon footprint will consequently decrease. Moreover, with the increase of the share of $P V$-battery systems to supply base stations, the self-sufficiency and power autonomy of telecommunication networks will be enhanced [37].

In order to maximize the power autonomy factor in telecommunication networks, the drawn power from the main grid should be minimized. Hence, the second objective function $\left(O F_{2}\right)$ is defined as follows:

$$
O F_{2}=\max \left\{\left[\frac{1}{H} \sum_{t=1}^{H}\left(\frac{P_{\text {PV2Load }}^{t}+P_{\text {Bat } 2 \text { Load }}^{t}}{P_{\text {load }}^{t}}\right)\right] \times 100\right\}
$$

where $P_{P V 2 L o a d}^{t}$ and $P_{\text {Batt2Load }}^{t}$ are, respectively, the hourly $P V$ and battery power share for supplying the load. $P_{\text {load }}^{t}$ is the hourly electricity demand of the base station.

\subsection{Technical Constraints}

Beside the battery constraints, one of the most important requirements in power management of base stations is the balance of electricity demand and supply as in the following [39]:

$$
P_{P V}^{t}+P_{\text {Batt }}^{t}+P_{\text {grid }}^{t}=P_{\text {load }}^{t}
$$

where $P_{P V}^{t}$ and $P_{B a t t}^{t}$ are the hourly power of $P V$ panels and battery, respectively.

\subsection{Power Dispatch Strategy}

The flowchart of the selected power dispatch strategy is illustrated in Figure 3. When the $P V$ generation is more than the load demand, after supplying the load, the extra energy will be stored in the battery if it is not fully charged. Any surplus energy will be delivered to the electric grid. If the $P V$ cannot provide enough energy to supply the load, the first choice is to discharge the battery. If there is not enough energy stored in the battery, then the electricity will be purchased from the main grid such that the power balance be satisfied.

By applying this power dispatch strategy, the dependency of the telecommunication network on the power grid will reduce and this results in the reliability increase of the system. Moreover, this strategy can also be implemented in cases in which the electricity grid is not available. In this situation, when the $P V$-battery system cannot satisfy the demand, some forms of green programmable energy sources such as hydrogen and fuel cells can be a used [40]. 


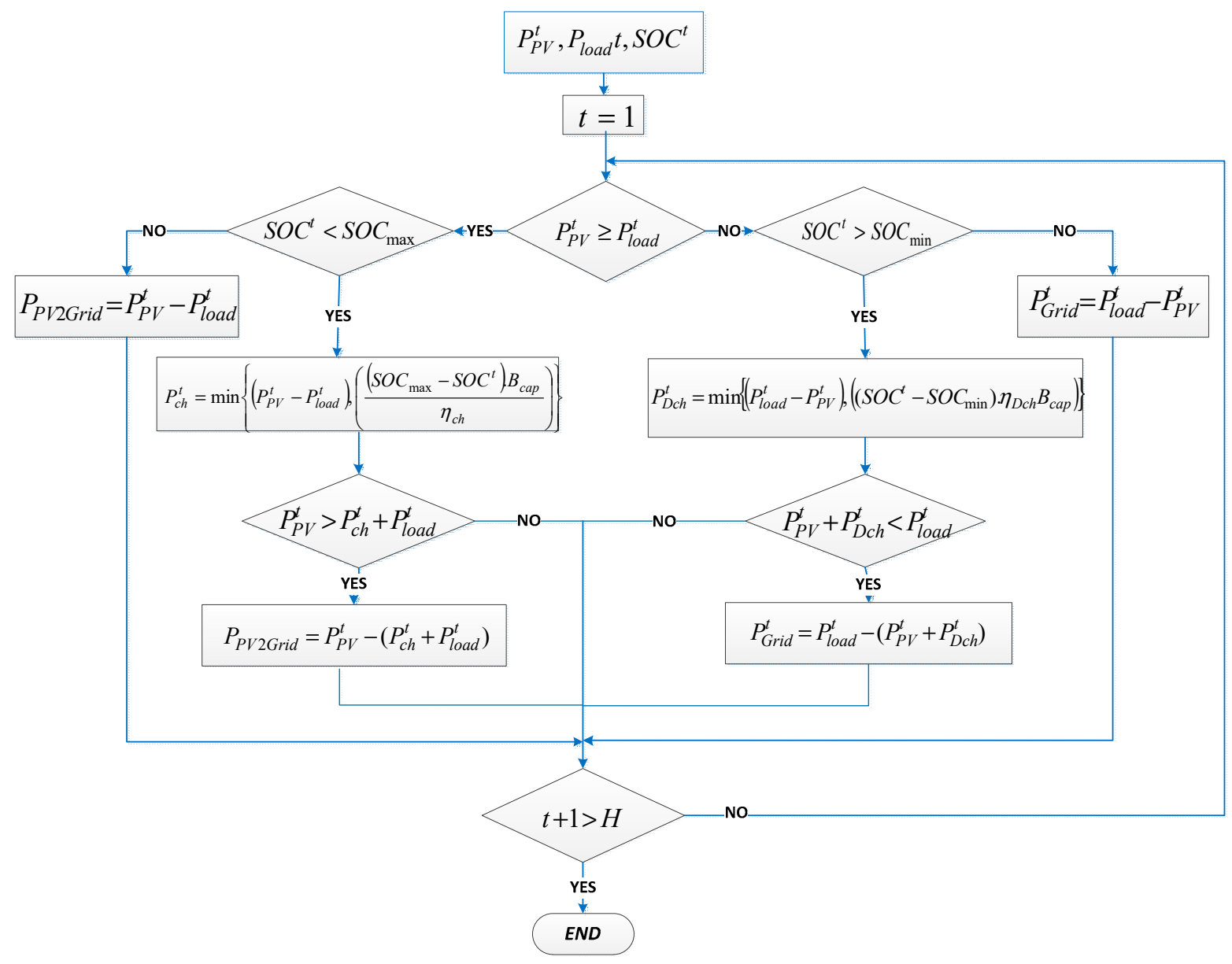

Figure 3. Flowchart of the power dispatch strategy.

\section{Multi-Objective JAYA Algorithm}

In order to determine the optimal size and installation (tilt and azimuth) angles of $P V$ panels and the battery capacity to power base stations, a multi-objective optimization framework is proposed in this section. As is mentioned in Section 3, the objectives are minimization of the total financial cost as well as maximization of the power autonomy factor.

The main advantage of using meta-heuristic algorithms in order to solve multiobjective problems is that they deal with a set of feasible solutions, which allows finding different solutions in the Pareto-optimal front by executing the algorithm only once. Moreover, meta-heuristic algorithms are not sensitive to the Pareto front pattern and continuity, which is one of the drawbacks of mathematical programming [41,42]. In order to solve the considered base station power management problem, the multi-objective version of the JAYA algorithm is proposed.

\subsection{JAYA Algorithm}

Compared to other meta-heuristic algorithms, the JAYA algorithm is simpler and more rapid while there is no need to tune the algorithmic parameters $[36,43,44]$; hence, the JAYA algorithm is applied in this paper.

The JAYA algorithm proposed by R. Venkata Rao [43] is selected due to its simplicity and rapidity, and as there is no need to have any information about control parameters. The major convenience of the JAYA algorithm is its independence in tuning and controlling the algorithmic parameters. Moreover, based on a detailed comparison between the PSO algorithm and the JAYA algorithm in [36], it is concluded that the JAYA algorithm is more advantageous to be used in solving multi-objective optimization problems. 
If $f(x)$ is considered as the objective function to be minimized, it is assumed that $m$ is the number of design variables (i.e., $i=1,2, \ldots, m$ ) in each iteration iter, and $n$ is the number of solutions (i.e., the size of the population $j=1,2, \ldots, n$ ). The best solution has the lowest value of $f(x)$ in solution queues and the worst solution has the maximum value of $f(x)$. Considering $\vec{X}_{i, j, i t e r}$ as the $i$ th variable for the $j$ th solution in iterth iteration, $\vec{X}_{i, j, i t e r}$ is modified according to the following [36]:

$$
X_{i, j, i t e r}^{\prime}=X_{i, j, i t e r}+r_{1 i, i t e r}\left(X_{i, b e s t, i t e r}-X_{i, j, i t e r}\right)-r_{2 i, i t e r}\left(X_{i, \text { worst }, \text { iter }}-X_{i, j, i t e r}\right)
$$

where $X_{i, b e s t, i t e r}$ is the $i$ th variable in best solutions in iterth iteration, and $X_{i, \text { worst, } i t e r}$ is the $i$ th variable in worst solutions in iterth iteration. $X_{i, j, i t e r}^{\prime}$ is the modified version of $X_{i, j, i t e r}$; and $r_{1 i, i t e r}$ and $r_{2 i, i t e r}$ are two random values in range $[0,1] . r_{1 i, i t e r}\left(X_{i, b e s t, i t e r}-X_{i, j, i t e r}\right)$ expresses the tendency of the solution to approach to the best solution, while $r_{2 i, i t e r}\left(X_{i, \text { worst }, \text { iter }}-X_{i, j, i t e r}\right)$ shows the trend of the solution to get far from the worst solution. If $X_{i, j, i t e r}^{\prime}$ leads to a better objective function value than that of $X_{i, j, i t e r}$, it is acceptable. At the end of each iteration, best solutions based on the values of the objective function are preserved and will be considered as the population for the next iteration. The best and worst solutions are determined in the recent preserved population for the next iteration. This procedure will continue until the termination criterion is satisfied.

\subsection{Multi-Objective JAYA}

In the design of the $P V$-battery system power supply for base stations, a multi-objective JAYA is applied to optimize both total cost and power autonomy factor. However, in order to make the JAYA algorithm suitable for multi-objective optimization problems, the concept of Pareto dominance is associated to generate non-dominated (Pareto-optimal) solutions, which results in Pareto fronts. At the end of each iteration of the multi-objective JAYA, the updated Pareto-optimal solutions are stored in a repository [45]. The steps of the proposed multi-objective framework are as follows:

Step 1 . Specify hourly solar irradiations, ambient temperature, geographical location, load profile, the battery specification, the design variables ranges, number of variables, and the termination criterion.

Step 2. Generate initial solutions in the feasible design variable range based on the following:

$$
X=X_{\min }+\text { rand } \cdot\left(X_{\max }-X_{\min }\right)
$$

where $X$ is an array of variables considered as a solution including the battery capacity, the area of installed $P V$ panels, installation angles, battery charge and discharge rates, and the exchanged power with the main grid; $X_{\min }$ and $X_{\max }$ are, respectively, the lower and upper bands of design variables; and rand is a random value in range $(0,1)$.

Step 3. Evaluate the initial solutions, i.e., check the constraints and calculate the objective functions.

Step 4. Determine and store non-dominated solutions in the repository.

Step 5. Determine the best and the worst solutions.

Step 6. Set iter $=1$

Step 7. In order to achieve new (modified) solutions, apply the JAYA algorithm based on (27) to each solution.

Step 8. For each new solution, check the battery constraints according to (15)-(18) and the power balance constraint (26). Calculate the objective functions for each new solution.

Step 9. If any of the new solutions is better than the current ones, replace the current solution by the corresponding modified solution.

Step 10. The non-dominated solutions in the modified solutions are identified and stored in the repository. The best and worst solutions are then determined among the stored solutions.

Step 11. Check the termination criterion and if satisfied, terminate the algorithm and go to Step 12; otherwise, set iter $=$ iter +1 and return to Step 7 . 
Step 12. Print the solutions in the repository as the Pareto-optimal front.

\section{Simulation Results}

In order to verify the effectiveness of the proposed approach, it is applied to three cases with different availability of solar power, namely, Aalborg, Denmark, Malaga, Spain, and Boujdour, Morocco to investigate the effect of environmental conditions. The hourly power consumption profiles of a base station in commercial and residential areas [23] on a weekday and weekend are shown in Figure 4. According to the results of [23], a reasonable choice for time slot for a one-year horizon of study is considered equal to one hour. The price for buying electricity based on time-of-use prices (TOU) are shown in Table 1, for Aalborg, Malaga, while the one-third of these prices is considered for the Boujdour, Morocco case. The cost of the $P V$ panel and the battery are considered $1350 \$ / \mathrm{kWp}$ and $500 \$ / \mathrm{kWh}$, respectively [37]. The considered yearly rental cost of the sites for commercial and residential areas are provided in Table 2 . The proposed method was implemented in a MATLAB environment. The population size (the number of candidate solutions) and number of maximum iterations in the JAYA algorithm are considered 50 and 200, respectively. Table 3 presents the system variables and their range.

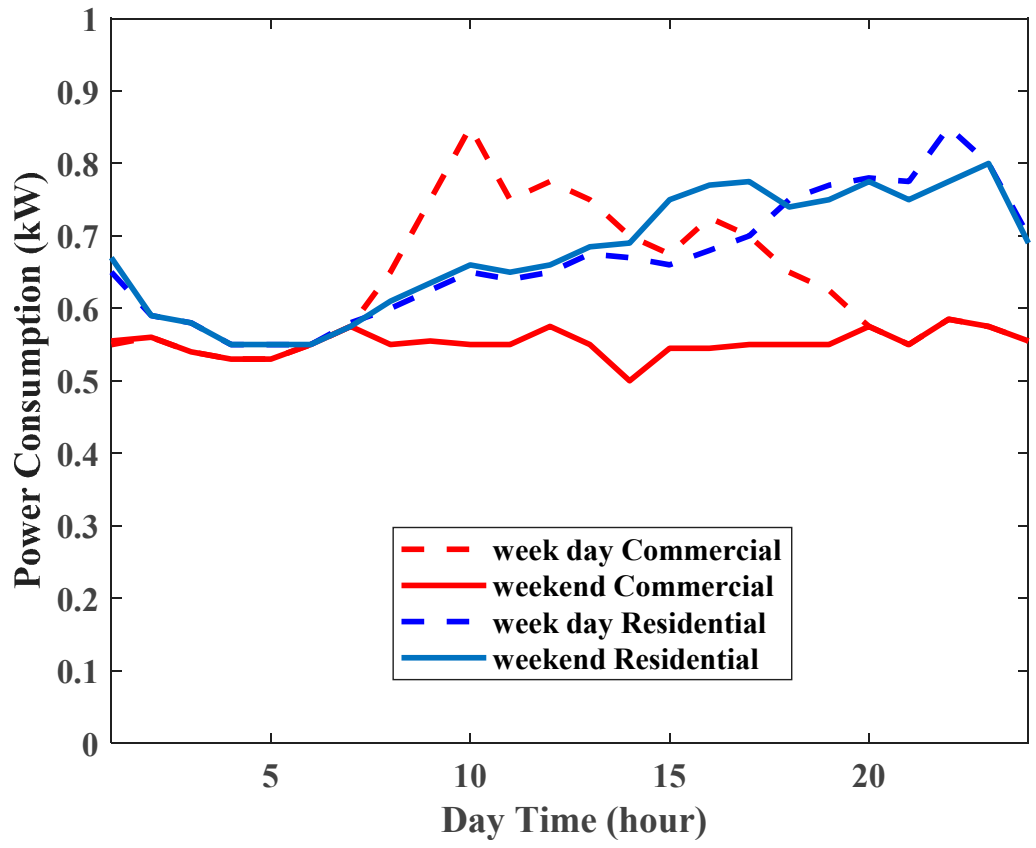

Figure 4. Weekday and weekend power consumption for a macro base station in commercial and residential areas.

Table 1. Electricity tariffs.

\begin{tabular}{ccc}
\hline Tariff Type & Time (Hours) & Price (\$/kWh) \\
\hline Peak & $9-20$ & 0.25 \\
\hline Off-peak & $0-9,20-24$ & 0.23 \\
\hline Feed-in & $0-24$ & 0.1 \\
\hline
\end{tabular}


Table 2. Rental cost for base station sites.

\begin{tabular}{cccccc}
\hline \multicolumn{2}{c}{ Rental Cost $\mathbf{( \$ \mathbf { m } ^ { \mathbf { 2 } } )}$} \\
\hline \multicolumn{2}{c}{ Aalborg } & \multicolumn{2}{c}{ Malaga } & \multicolumn{2}{c}{ Boujdour } \\
\hline $\begin{array}{c}\text { Residential } \\
\text { area }\end{array}$ & $\begin{array}{c}\text { Commercial } \\
\text { area }\end{array}$ & $\begin{array}{c}\text { Residential } \\
\text { area }\end{array}$ & $\begin{array}{c}\text { Commercial } \\
\text { area }\end{array}$ & $\begin{array}{c}\text { Residential } \\
\text { area }\end{array}$ & $\begin{array}{c}\text { Commercial } \\
\text { area }\end{array}$ \\
\hline 100 & 200 & 50 & 100 & 33 & 66 \\
\hline
\end{tabular}

Table 3. System variables and their range.

\begin{tabular}{cccc}
\hline Variable & Symbol & Unit & Variable Range \\
\hline Peak $P V$ power & $P_{P V}^{P e a k}$ & $\mathrm{kWp}$ & $(0-11.25)$ \\
\hline Azimuth angle & $\theta$ & degree & $(-90-90)$ \\
\hline Tilt angle & $\gamma$ & degree & $(0-90)$ \\
\hline Battery capacity & $B_{c a p}$ & $\mathrm{kWh}$ & $(0-30)$ \\
\hline State of charge & $S O C$ & $\%$ & $(10-90$ \\
\hline
\end{tabular}

Figure 5 demonstrates the Pareto-optimal solutions of different power autonomy levels at different values of total cost for a $P V$-battery system-powered base station in a commercial area in the Aalborg, Malaga and Boujdour case studies. As is observed, a high level of power autonomy leads to a higher total cost, and vice versa. According to Figure 5 to achieve a $70 \%$ power autonomy factor for Aalborg, the total cost is $\$ 35,000$, while for Malaga and Boujdour, the total cost is $\$ 15,000$ and $\$ 12,000$, respectively.

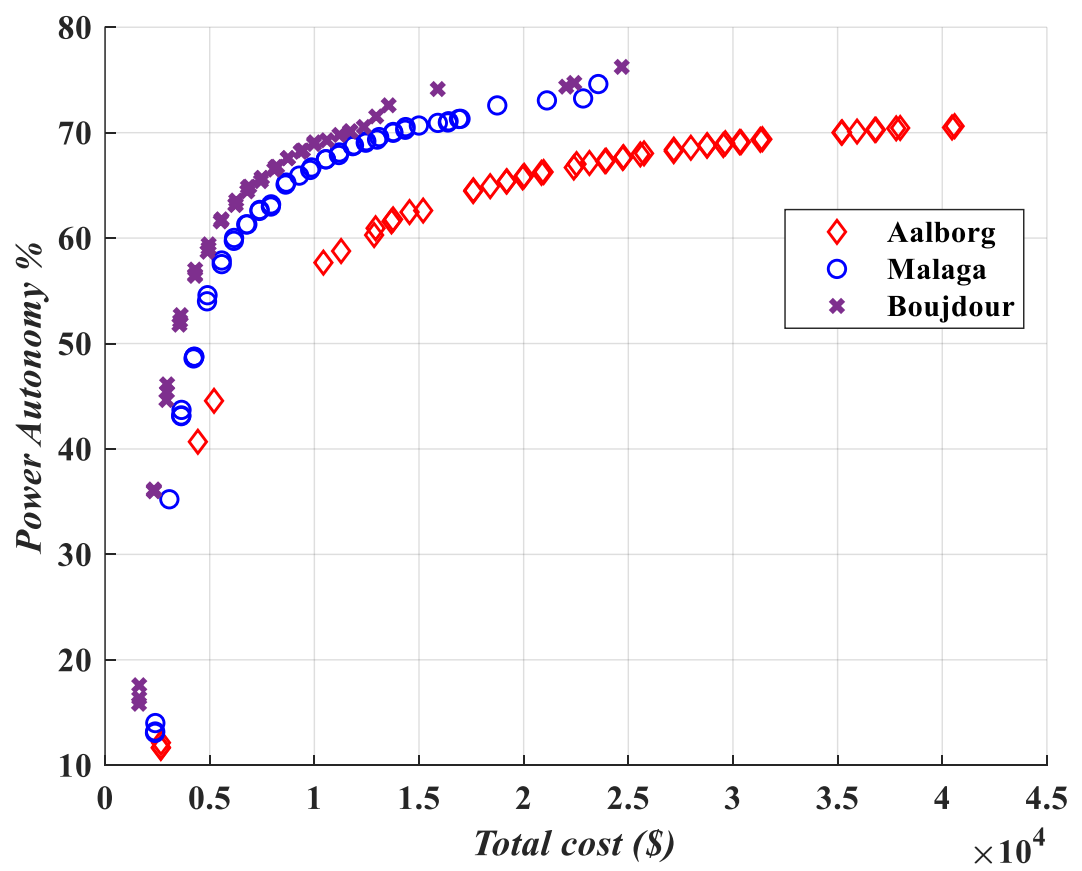

Figure 5. Pareto-optimal solutions of different power autonomy levels at different values of total cost in a commercial area.

Figures 6-8 respectively show the values of total cost and power autonomy factor for a variety of peak $P V$ power and battery capacity values for Malaga, Aalborg and Boujdour in commercial area case studies. Accordingly, as an example, for achieving a power autonomy factor of $70 \%$, in the case of Malaga, installation of a $4.9 \mathrm{kWp} P V$ panel and a $5 \mathrm{kWh}$ battery is required. In the case of Aalborg, installation of a $10.5 \mathrm{kWp} \mathrm{PV}$ panel and a $15 \mathrm{kWh}$ 
battery is required, while in the case of Boujdour, installation of a $3.4 \mathrm{kWp} P V$ panel and a $9 \mathrm{kWh}$ battery is required.

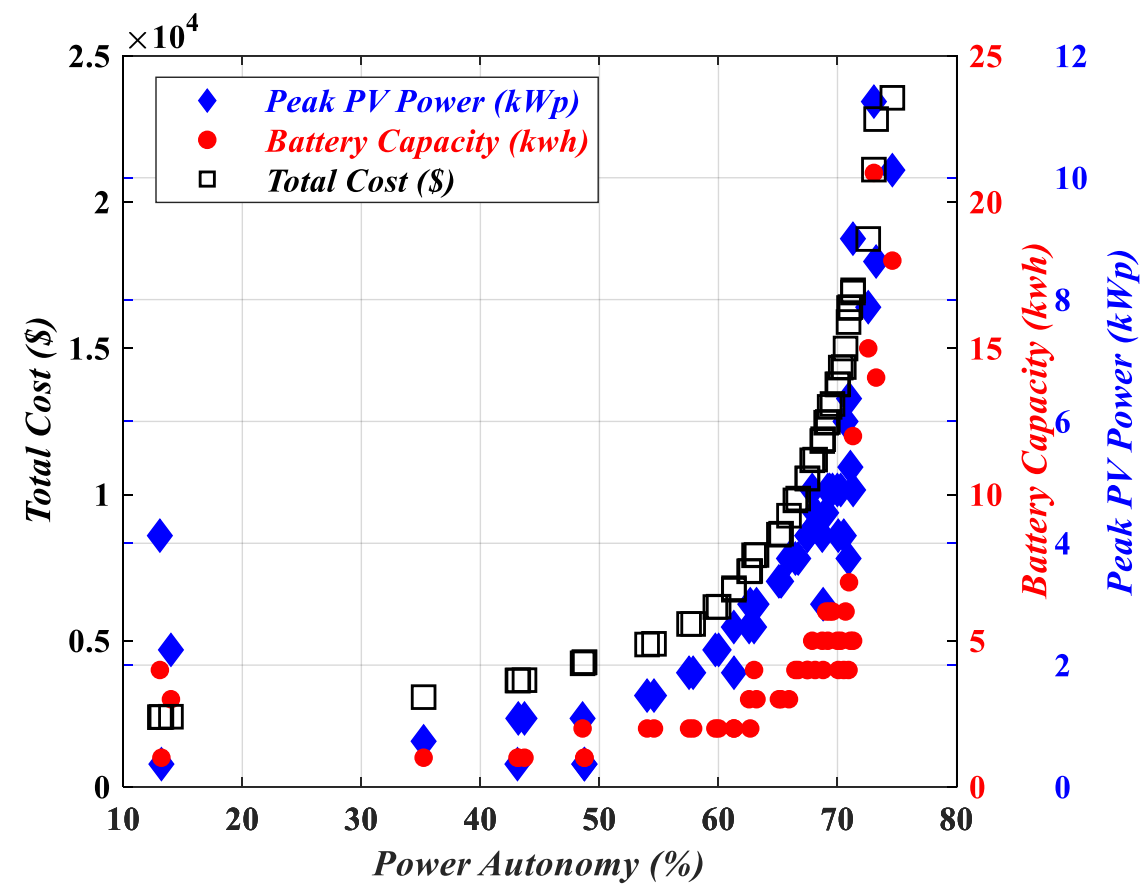

Figure 6. Total cost and power autonomy factor for a variety of $P V$ panel installation areas and battery capacity values for Malaga (commercial area).

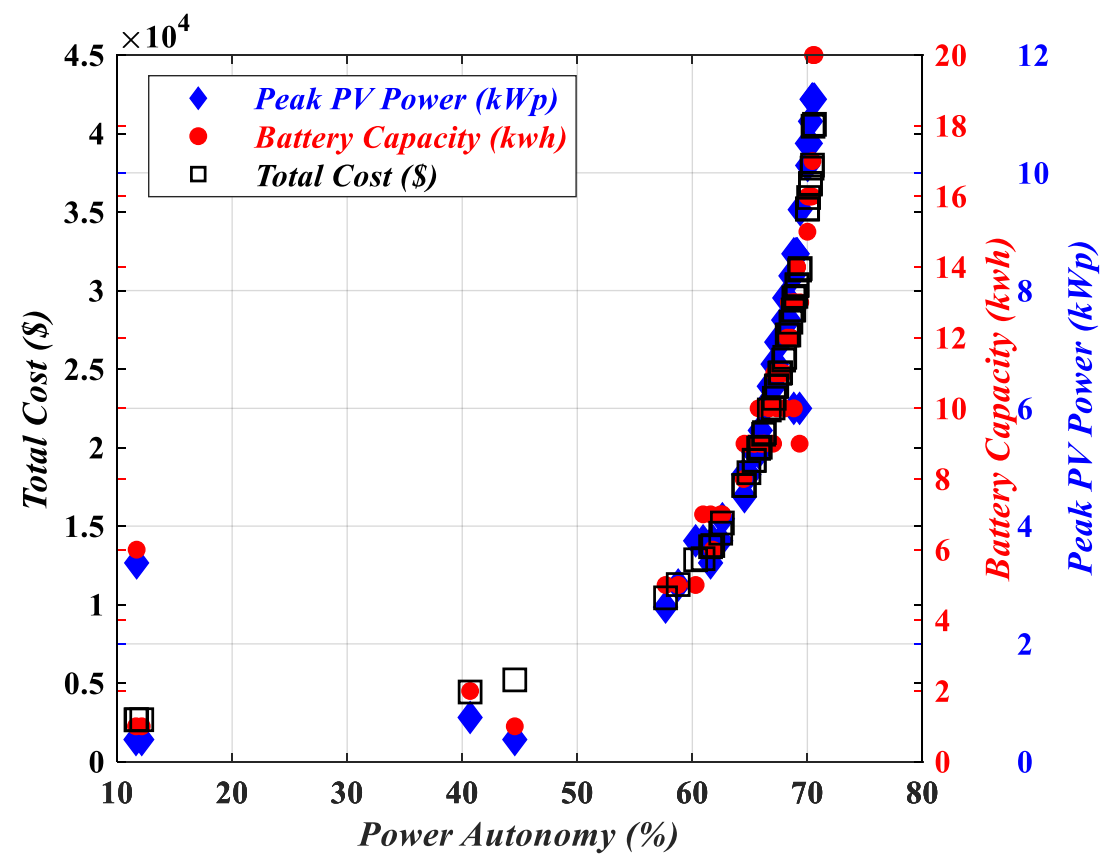

Figure 7. Total cost and power autonomy factor for a variety of $P V$ panel installation areas and battery capacity values for Aalborg (commercial area). 


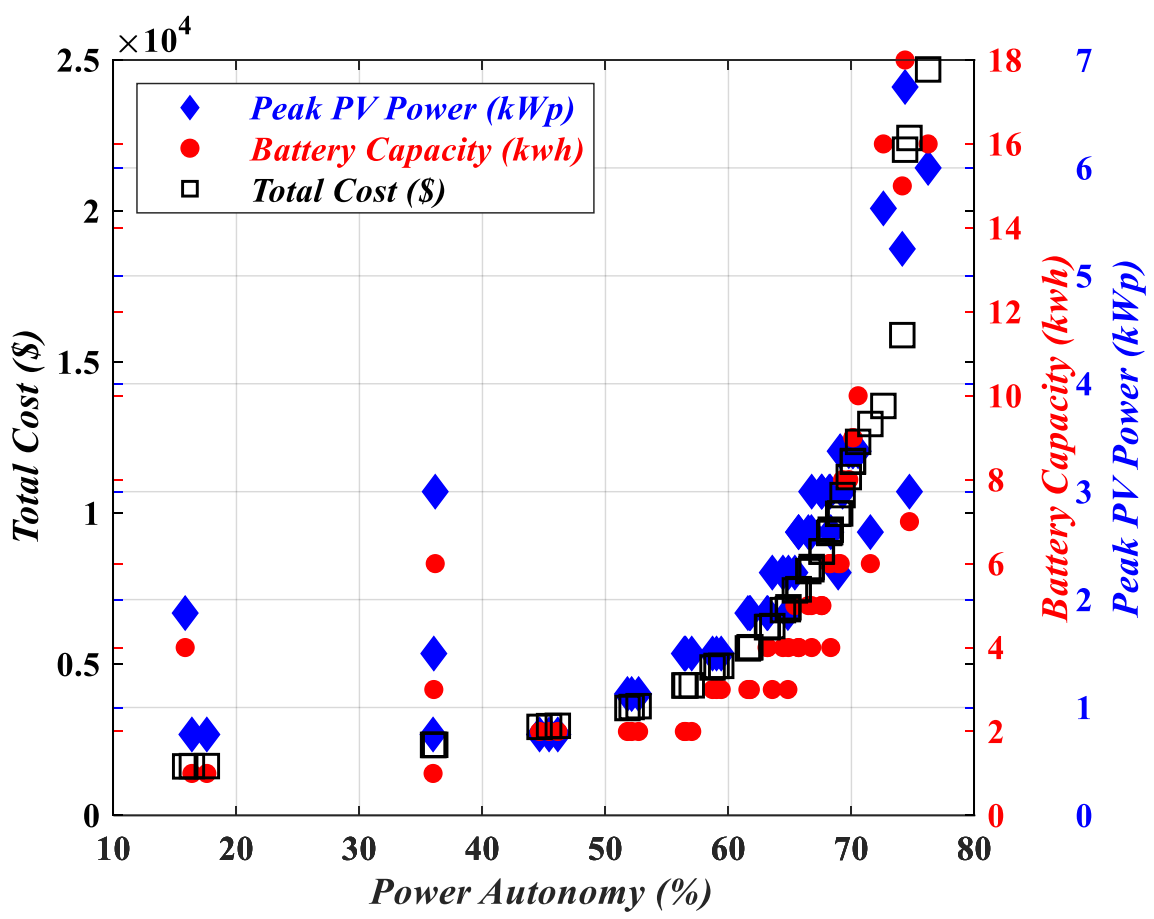

Figure 8. Total cost and power autonomy factor for a variety of $P V$ panel installation areas and battery capacity values for Boujdour (commercial area).

Figure 9 demonstrates the Pareto-optimal solutions of different power autonomy levels at different values of total cost for a $P V$-battery system-powered base station in a residential area in Aalborg, Malaga and Boujdour. According to Figure 9, in the case of Aalborg, it is difficult to achieve a power autonomy factor of $70 \%$ due to the low solar irradiation. However, in order to achieve a maximum power autonomy factor of $68 \%$ in Aalborg, the total cost equals $\$ 35,000$. For Malaga, the maximum achievable power autonomy factor is $71 \%$ for a total cost of $\$ 24,000$. For Boujdour, the maximum achievable power autonomy factor is $73 \%$ for a total cost of $\$ 27,700$.

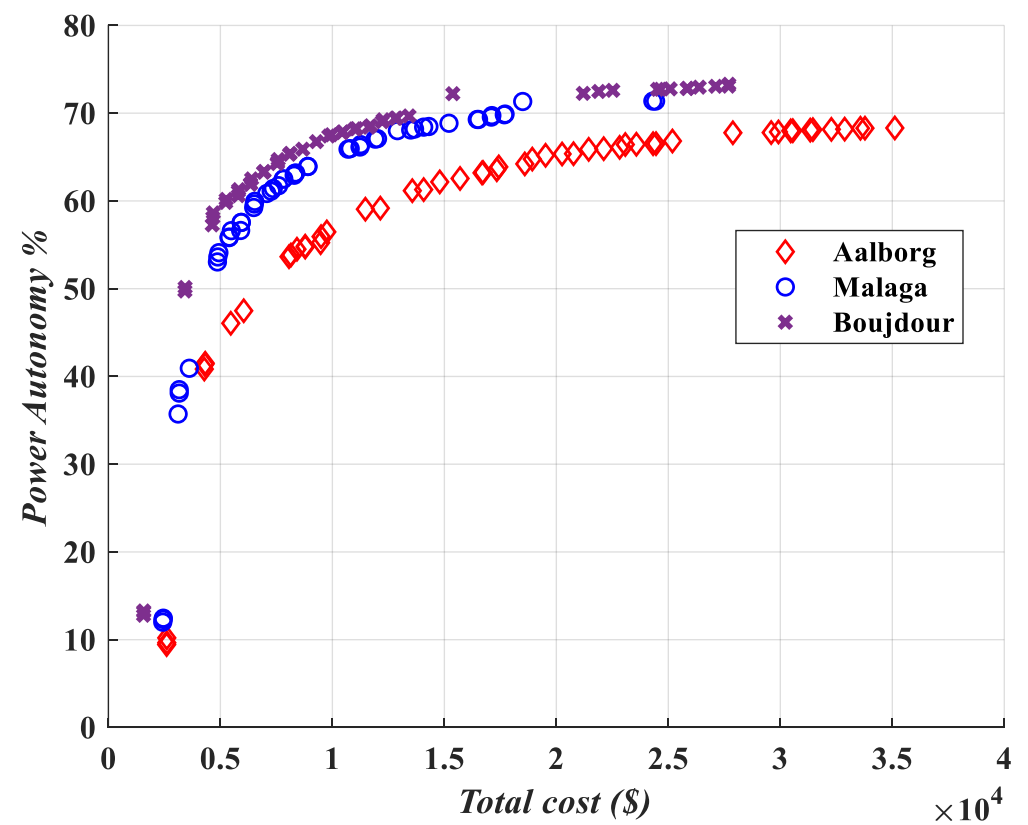

Figure 9. Pareto-optimal solutions of different power autonomy levels at different values of total cost in a residential area. 
Figures 10-12 respectively show the values of total cost and power autonomy factor for a variety of peak $P V$ power and battery capacity values for Malaga, Aalborg and Boujdour in residential area case studies. Accordingly, as an example, in the case of Malaga, to achieve a power autonomy factor of $68 \%$, installation of a $5.3 \mathrm{kWp} P V$ panel and a $9 \mathrm{kWh}$ battery is required, which leads to a total cost of $\$ 12,900$. For the case study of Aalborg, in order to have a power autonomy factor of $68 \%$, installation of a $11.25 \mathrm{kWp} P V$ panel and a $19 \mathrm{kWh}$ battery is required, which leads to a total cost of $\$ 35,000$. In Boujdour, a $4.5 \mathrm{kWp}$ $P V$ panel and a $5 \mathrm{kWh}$ battery need to be installed, which leads to a total cost of $\$ 10,400$.

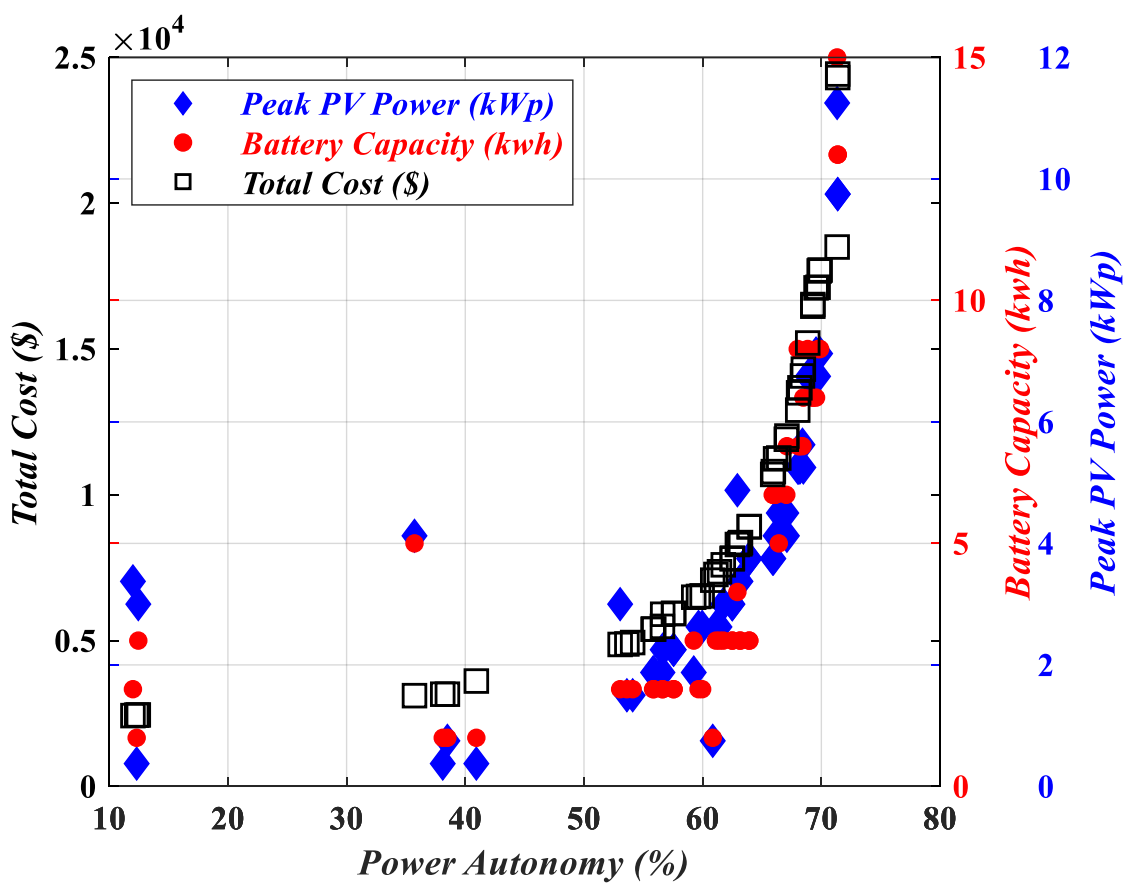

Figure 10. Total cost and power autonomy factor for a variety of $P V$ panel installation areas and battery capacity values for Malaga (residential area).

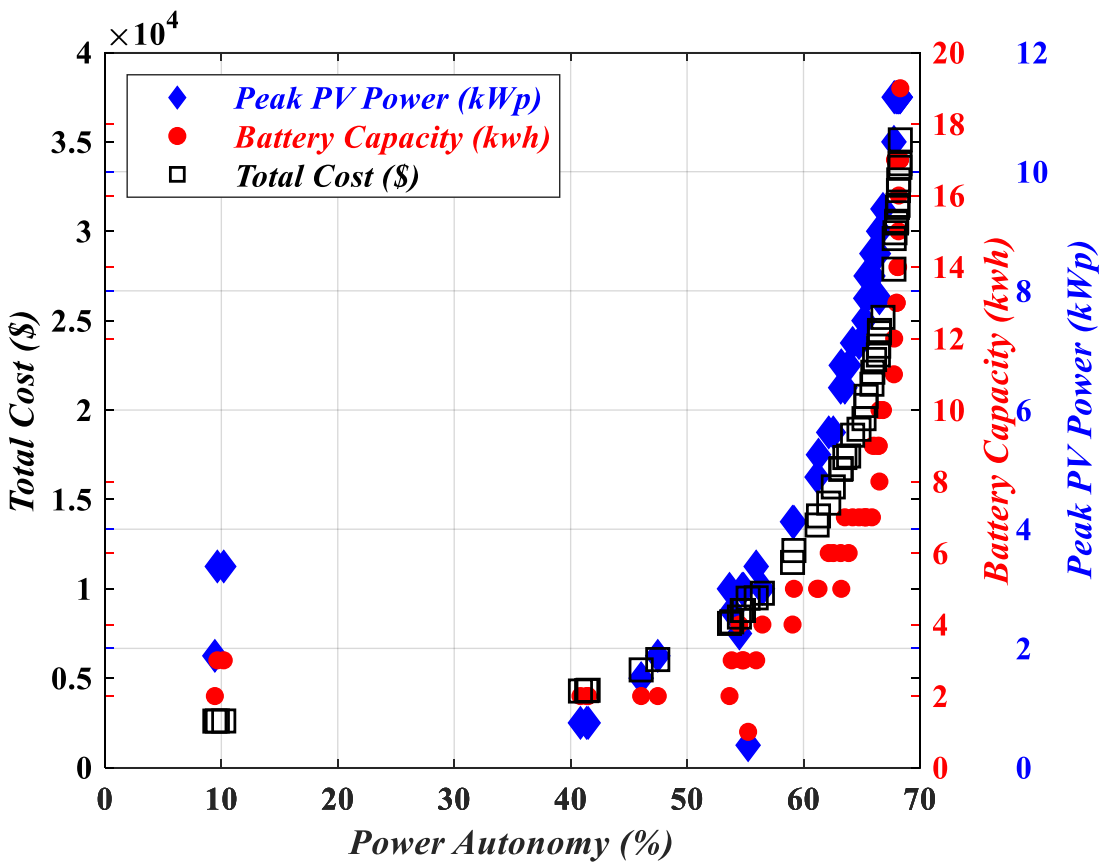

Figure 11. Total cost and power autonomy factor for a variety of $P V$ panel installation areas and battery capacity values for Aalborg (residential area). 


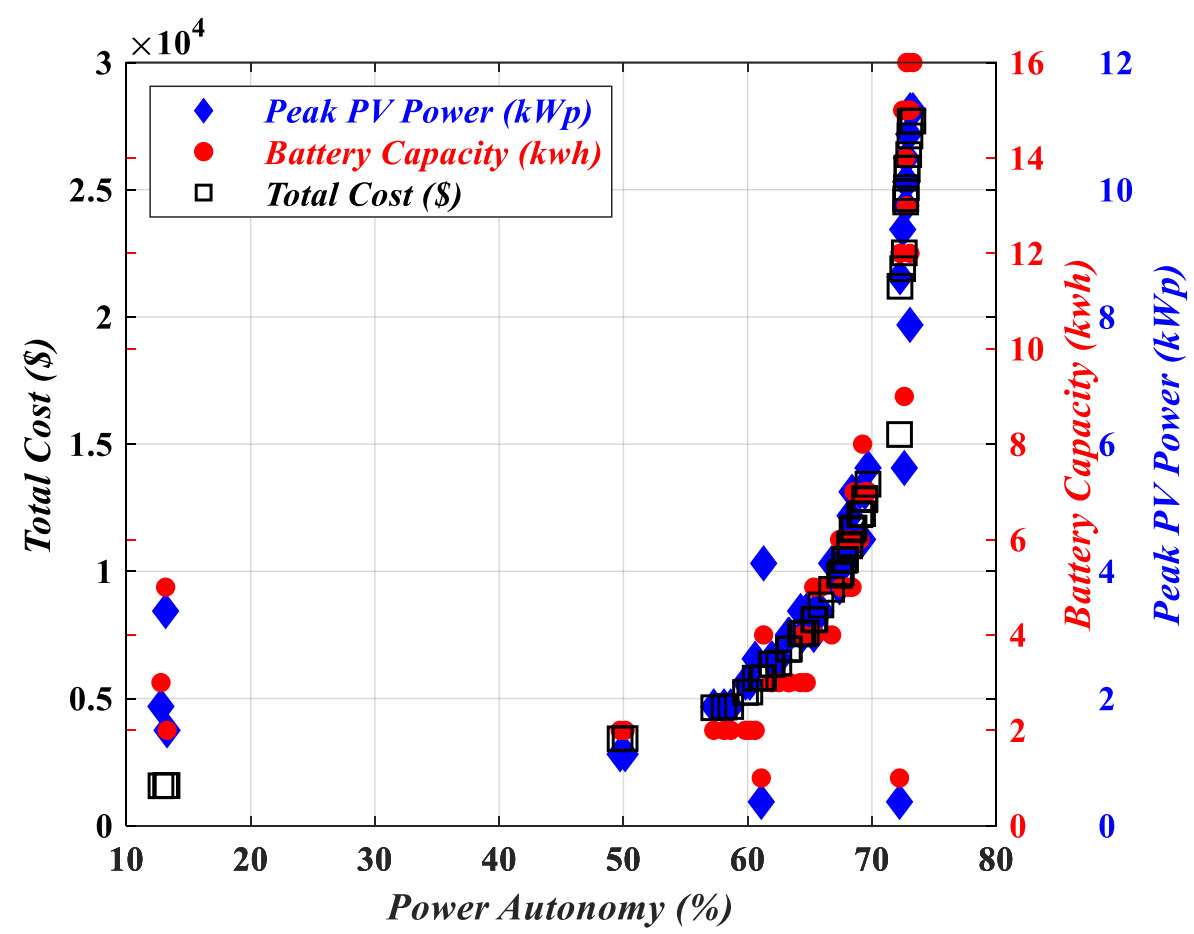

Figure 12. Total cost and power autonomy factor for a variety of $P V$ panel installation areas and battery capacity values for Boujdour (residential area).

According to Figures 5 and 9, solving the $P V$-battery dimensioning problem for supplying base stations in cellular networks leads to a set of solutions with different values of economic index (total cost) and self-sufficiency (power autonomy). Consequently, based on the priority of each of the mentioned indices, an MNO can adopt one of the solutions. If the economic aspect is of high importance, the adopted solution leads to a low power autonomy level; on the other hand, if the self-sufficiency aspect is more important, supplying the base station using a $P V$-battery system leads to a high economic cost. The MNO should always adopt a trade-off between these two approaches.

Based on the peak $P V$ power ranging from zero to $11.25 \mathrm{kWp}$ with an interval of $0.375 \mathrm{kWp}$ and the battery capacity ranging from $0 \mathrm{kWh}$ to $30 \mathrm{kWh}$ for azimuth and tilt angles $-13^{\circ}$ and $19^{\circ}$, Figures 13 and 14 respectively illustrate the annual total cost yield and power autonomy factor for the case study of a commercial area in Aalborg. According to the results, a higher power autonomy factor is achievable with higher total cost since these considered objectives for the optimization problem are in conflict.

According to Figures 13 and 14, if the $P V$ panel with the maximum peak power is installed in a commercial area in Aalborg, when the battery capacity is increased, it only leads to a higher total cost value, while the maximum achievable power autonomy factor does not improve.

Figures 15-17 illustrate the annual daily maximum achievable power autonomy for Malaga, Aalborg, and Boujdour, respectively. It is shown in Figure 15 that the maximum value of power autonomy factor for Malaga is between 70 to $80 \%$, which is achieved during summer. However, the lower values of power autonomy factor are during winter and autumn. 


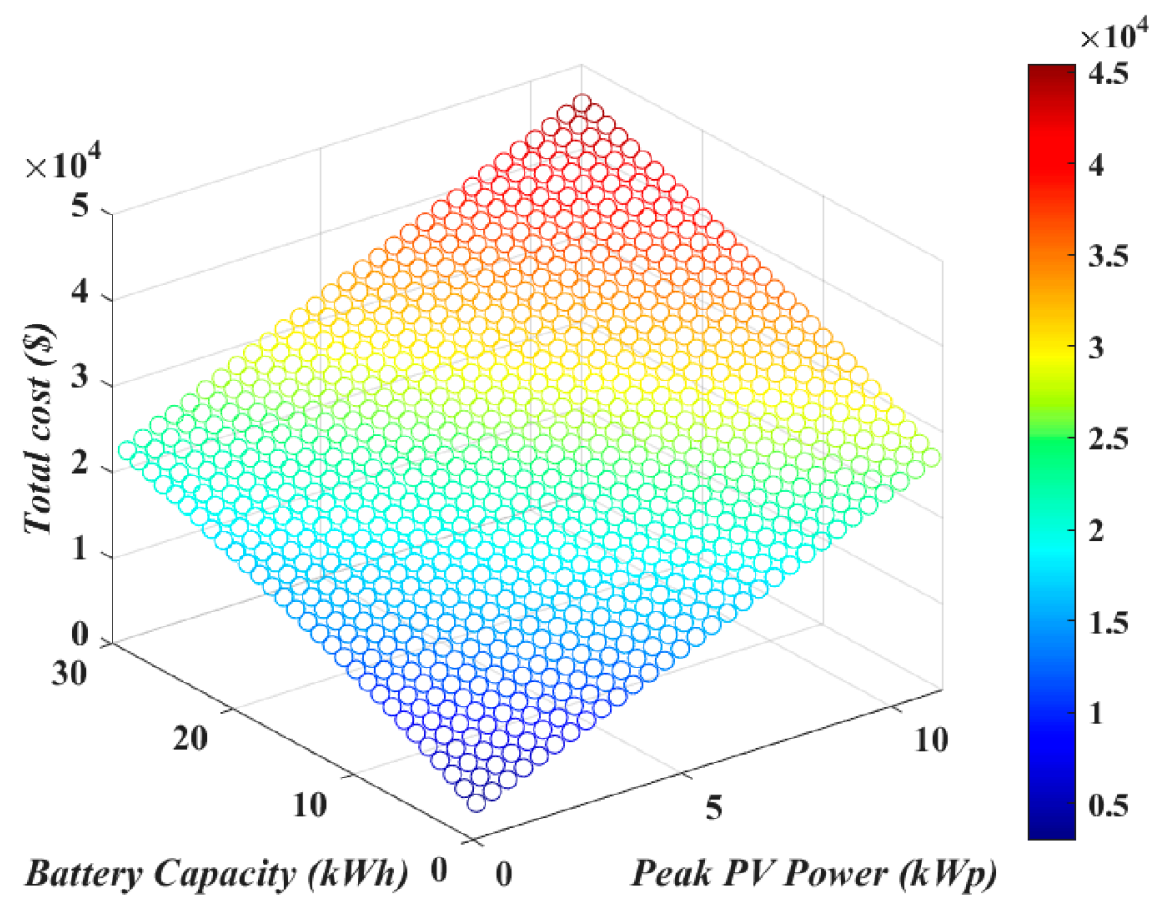

Figure 13. Total cost for a variety of $P V$-battery system combinations to supply a commercial base station in Aalborg.

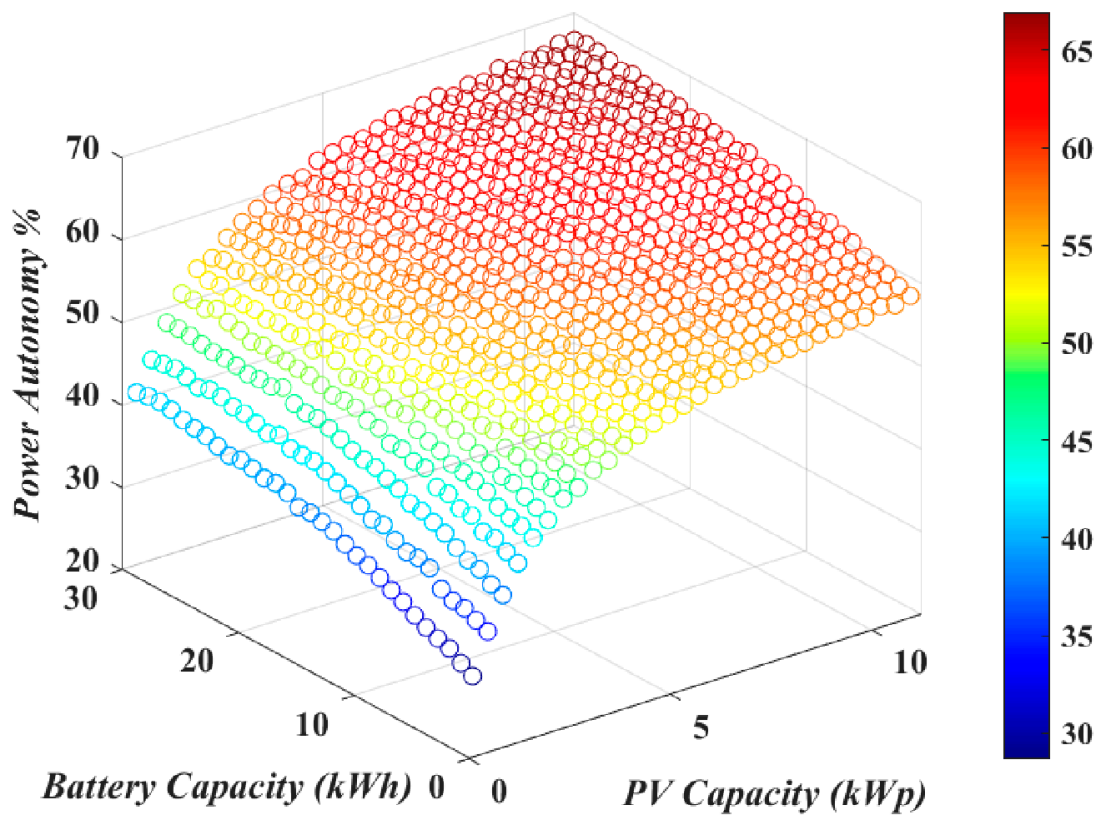

Figure 14. Power autonomy factor performance for different $P V$-battery system combinations to supply a commercial base station in Aalborg. 


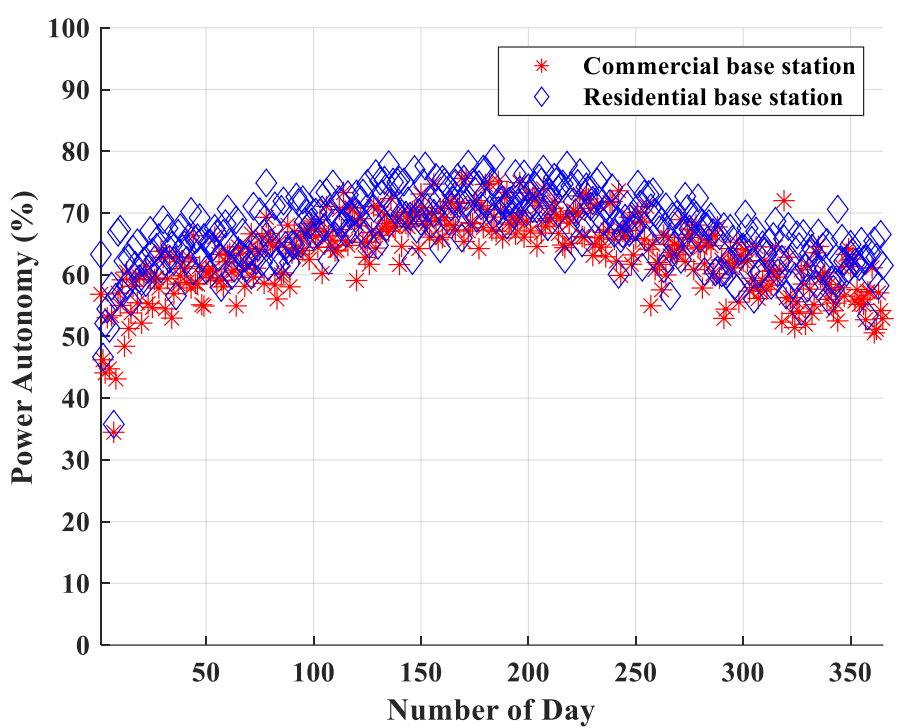

Figure 15. Power autonomy factor for Malaga throughout the year.

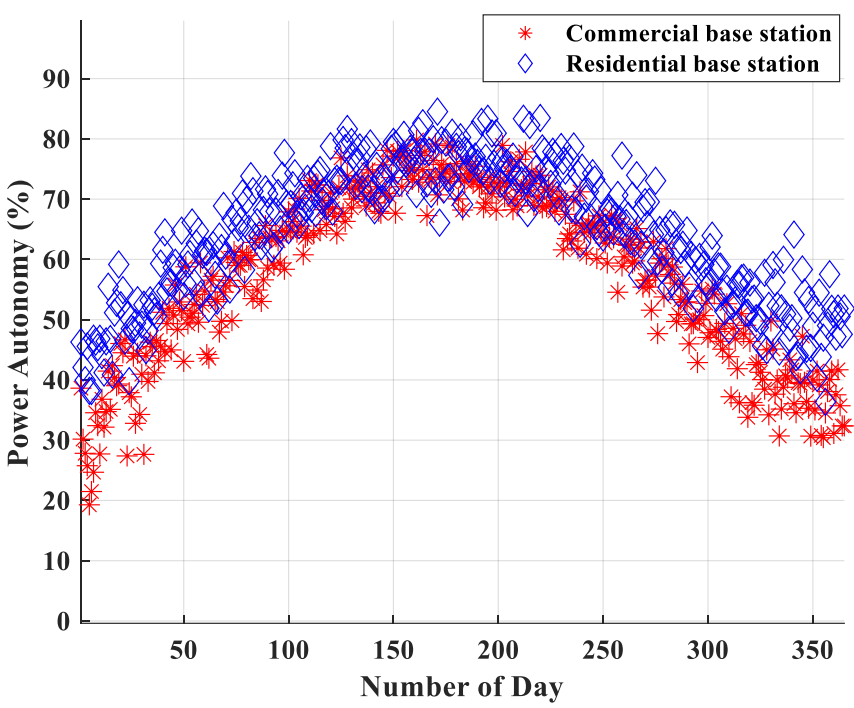

Figure 16. Power autonomy factor for Aalborg throughout the year.

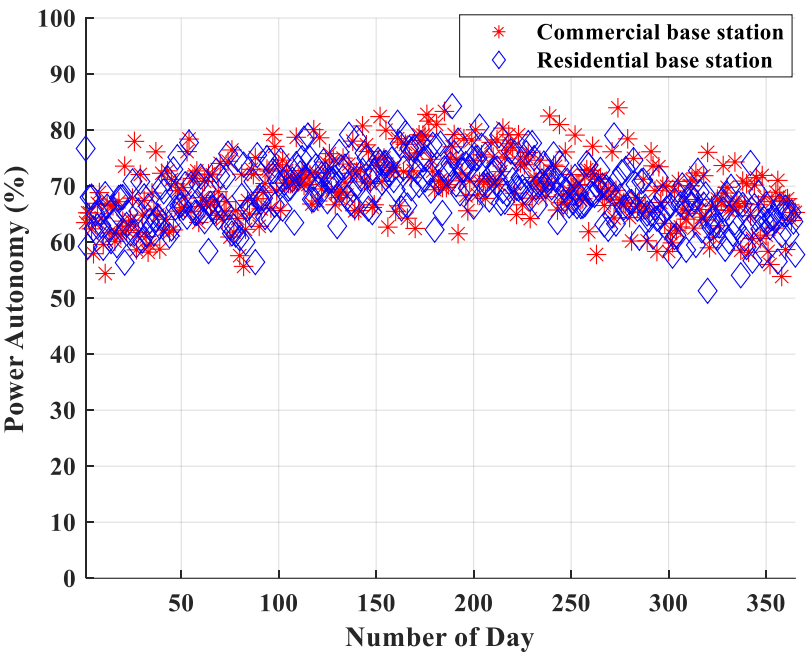

Figure 17. Power autonomy factor for Boujdour throughout the year. 
According to Figure 16, it is observed that for Aalborg during winter and autumn, since there is less solar availability, a lower daily power autonomy factor is achieved. In summer, however, the daily power autonomy factor can reach to values higher than $70 \%$.

From Figure 17, for Boujdour, the highest values of power autonomy factor during summer are higher than $80 \%$, while these values are between 50 to $60 \%$ during winter and autumn.

\section{Conclusions}

The densification of 5G cellular telecommunication networks leads to an extensive energy demand. An advantageous solution to power base stations is RESs, which can both decrease the emission and operational cost while increasing the power autonomy of the system. However, due to the intermittent nature of RESs, an optimal dimension of renewable-based plus battery power supply is essential to power cellular networks self-sufficiently. In this paper, an optimal method for designing a $P V$-battery system to supply base stations in cellular networks to maximize power autonomy and minimize the total cost of the system is presented. The effect of solar power availability on optimal $P V$-battery sizing is investigated by comparing results on three different geographical locations, and a detailed analysis of the results leads to the following observations. For achieving a power autonomy factor of $70 \%$, the total cost for the Aalborg case study is three times that of the total cost of Boujdour and two times that of Malaga. Consequently, in order to determine the optimal $P V$-battery system to supply base stations in cellular networks, the exact power generation of the supply system and consumption profiles of the base station deployment site should be available. Since the power supply of a grid-connected base station is investigated in this paper, future work can focus on solving the problem in a situation where a reliable power grid is not available; however, in cases that $100 \%$ power autonomy has not been achieved, another source, such as fuel cell, may be needed to power off-grid base stations. Furthermore, in order to decide on the highest economic design of the $P V$-battery system for supplying base stations in the next generation cellular telecommunication networks, different energy storage devices as well as a variety of battery technologies can be investigated.

Author Contributions: Conceptualization, M.J. and H.P.; methodology, M.J., H.P., and T.K.; software, M.J. and H.P.; validation, M.J., H.P. and T.K.; formal analysis, M.J.; investigation, M.J.; writingoriginal draft preparation, M.J.; writing—review and editing, T.K., D.S., S.S. and J.M.G.; supervision, T.K., D.S., S.S. and J.M.G. All authors have read and agreed to the published version of the manuscript.

Funding: This research was funded by the European Union's Horizon 2020 research and innovation programme under the Marie Sklodowska-Curie grant agreement No 812991.

Institutional Review Board Statement: Not applicable.

Informed Consent Statement: Not applicable.

Data Availability Statement: Not applicable.

Conflicts of Interest: The authors declare no conflict of interest.

\section{References}

1. Han, D.; Li, S.; Peng, Y.; Chen, Z. Energy sharing-based energy and user joint allocation method in heterogeneous network. IEEE Access 2020, 8, 37077-37086. [CrossRef]

2. Tran, H.-V.; Kaddoum, G.; Diamantoulakis, P.D.; Abou-Rjeily, C.; Karagiannidis, G.K. Ultra-small cell networks with collaborative RF and lightwave power transfer. IEEE Trans. Commun. 2019, 67, 6243-6255. [CrossRef]

3. Chamola, V.; Sikdar, B. Solar powered cellular base stations: Current scenario, issues and proposed solutions. IEEE Commun. Mag. 2016, 54, 108-114. [CrossRef]

4. Rokrok, E.; Javidsharifi, M.; Pourroshanfekr, H.; Javidsharifi, B. Adaptive Nonlinear Control Scheme for Three-Phase GridConnected PV Central Inverters. In Proceedings of the 29th International Power System Conference (PSC), Terhan, Iran, 27 October 2014; pp. 1-7. 
5. Marsan, M.G.A.; Bucalo, G.; Di Caro, A.; Meo, M.; Zhang, Y. Towards Zero Grid Electricity Networking: Powering BSs with Renewable Energy Sources. In Proceedings of the 2013 IEEE International Conference on Communications Workshops (ICC), Budapest, Hungary, 9-13 June 2013; pp. 596-601.

6. Meo, M.; Zhang, Y.; Gerboni, R.; Marsan, M.A. Dimensioning the power supply of a LTE macro BS connected to a PV panel and the power grid. In Proceedings of the 2015 IEEE International Conference on Communications (ICC), London, UK, 8-12 June 2015 pp. $178-184$.

7. Ahmed, F.; Naeem, M.; Ejaz, W.; Iqbal, M.; Anpalagan, A.; Kim, H.S. Renewable energy assisted traffic aware cellular base station energy cooperation. Energies 2018, 11, 99. [CrossRef]

8. Alsharif, M.H.; Kim, J.; Kim, J.H. Green and sustainable cellular base stations: An overview and future research directions. Energies 2017, 10, 587. [CrossRef]

9. Kusakana, K.; Vermaak, H.J. Hybrid renewable power systems for mobile telephony base stations in developing countries. Renew. Energy 2013, 51, 419-425. [CrossRef]

10. Aris, A.M.; Shabani, B. Sustainable power supply solutions for off-grid base stations. Energies 2015, 8, 10904-10941. [CrossRef]

11. Khare, V.; Nema, S.; Baredar, P. Status of solar wind renewable energy in India. Renew. Sustain. Energy Rev. 2013, 27, 1-10. [CrossRef]

12. Song, J.; Krishnamurthy, V.; Kwasinski, A.; Sharma, R. Development of a Markov-chain-based energy storage model for power supply availability assessment of photovoltaic generation plants. IEEE Trans. Sustain. Energy 2012, 4, 491-500. [CrossRef]

13. Leonardi, G.; Meo, M.; Marsan, M.A. Markovian Models of Solar Power Supply for a LTE Macro BS. In Proceedings of the 2016 IEEE International Conference on Communications (ICC) Kuala Lumpur, Malaysia, 22-27 May 2016; pp. 1-7.

14. Chamola, V.; Sikdar, B. Outage Estimation for Solar Powered Cellular Base Stations. In Proceedings of the 2015 IEEE International Conference on Communications (ICC), London, UK, 8-12 June 2015; pp. 172-177.

15. Fletscher, L.A.; Suárez, L.A.; Grace, D.; Peroni, C.V.; Maestre, J.M. Energy-aware resource management in heterogeneous cellular networks with hybrid energy sources. IEEE Trans. Netw. Serv. Manag. 2018, 16, 279-293. [CrossRef]

16. Tang, L.; Hu, H. Multi-Objective Optimization of User Association in HetNets with Hybrid Power Supply. IEEE Trans. Green Commun. Netw. 2019, 3, 933-941. [CrossRef]

17. Gambín, Á.F.; Scalabrin, M.; Rossi, M. Online power management strategies for energy harvesting mobile networks. IEEE Trans. Green Commun. Netw. 2019, 3, 721-738. [CrossRef]

18. Ghazzai, H.; Yaacoub, E.; Kadri, A.; Yanikomeroglu, H.; Alouini, M.-S. Next-generation environment-aware cellular networks: Modern green techniques and implementation challenges. IEEE Access 2016, 4, 5010-5029. [CrossRef]

19. Benda, D.; Sun, S.; Chu, X.; Quek, T.Q.; Buckley, A. PV cell angle optimization for energy generation-consumption matching in a solar powered cellular network. IEEE Trans. Green Commun. Netw. 2017, 2, 40-48. [CrossRef]

20. Benda, D.; Sun, S.; Chu, X.; Buckley, A.; Quek, T.Q. PV cell orientation angles optimization for a base station equipped with several PV cells. IEEE Trans. Green Commun. Netw. 2019, 4, 194-208. [CrossRef]

21. Renga, D.; Meo, M. Dimensioning renewable energy systems to power mobile networks. IEEE Trans. Green Commun. Netw. 2019, 3, 366-380. [CrossRef]

22. De Souza, M.A.; de Souza Farias, F.; Kuribayashi, H.P.; Francês, C.R.; Costa, J.C.; Cardoso, D.L. A Photovoltaic System for Heterogeneous Networks: A Technical, Economic and Environmental Analysis. J. Commun. Inf. Syst. 2020, 35, 90-102. [CrossRef]

23. Da Silva, A.P.C.; Renga, D.; Meo, M.; Marsan, M.A. The impact of quantization on the design of solar power systems for cellular base stations. IEEE Trans. Green Commun. Netw. 2017, 2, 260-274. [CrossRef]

24. Chiaraviglio, L.; Amorosi, L.; Blefari-Melazzi, N.; Dell'Olmo, P.; Mastro, A.L.; Natalino, C.; Monti, P. Minimum Cost Design of Cellular Networks in Rural Areas With UAVs, Optical Rings, Solar Panels, and Batteries. IEEE Trans. Green Commun. Netw. 2019, 3, 901-918. [CrossRef]

25. Kaur, R.; Krishnasamy, V.; Kandasamy, N.K.; Kumar, S. Discrete multiobjective grey wolf algorithm based optimal sizing and sensitivity analysis of PV-wind-battery system for rural telecom towers. IEEE Syst. J. 2019, 14, 729-737. [CrossRef]

26. Suman, S.; De, S. Low complexity dimensioning of sustainable solar-enabled systems: A case of base station. IEEE Trans. Sustain. Comput. 2019, 5, 438-454. [CrossRef]

27. Jahid, A.; Monju, M.K.H.; Hossain, M.E.; Hossain, M.F. Renewable energy assisted cost aware sustainable off-grid base stations with energy cooperation. IEEE Access 2018, 6, 60900-60920. [CrossRef]

28. Piovesan, N.; Temesgene, D.A.; Miozzo, M.; Dini, P. Joint load control and energy sharing for autonomous operation of $5 \mathrm{~g}$ mobile networks in micro-grids. IEEE Access 2019, 7, 31140-31150. [CrossRef]

29. Jahid, A.; Hossain, M.S.; Monju, M.K.H.; Rahman, M.F.; Hossain, M.F. Techno-economic and energy efficiency analysis of optimal power supply solutions for green cellular base stations. IEEE Access 2020, 8, 43776-43795. [CrossRef]

30. Jahid, A.; Islam, M.S.; Hossain, M.S.; Hossain, M.E.; Monju, M.K.H.; Hossain, M.F. Toward energy efficiency aware renewable energy management in green cellular networks with joint coordination. IEEE Access 2019, 7, 75782-75797. [CrossRef]

31. Fortuna, L.; Nunnari, G.; Nunnari, S. A new fine-grained classification strategy for solar daily radiation patterns. Pattern Recognit. Lett. 2016, 81, 110-117. [CrossRef]

32. Huld, T.; Müller, R.; Gambardella, A. A new solar radiation database for estimating PV performance in Europe and Africa. Sol. Energy 2012, 86, 1803-1815. [CrossRef] 
33. Khatib, T.; Elmenreich, W. A model for hourly solar radiation data generation from daily solar radiation data using a generalized regression artificial neural network. Int. J. Photoenergy 2015, 2015. [CrossRef]

34. Al Garni, H.Z.; Awasthi, A.; Wright, D. Optimal orientation angles for maximizing energy yield for solar PV in Saudi Arabia. Renew. Energy 2019, 133, 538-550. [CrossRef]

35. Sidorov, D.; Muftahov, I.; Tomin, N.; Karamov, D.; Panasetsky, D.; Dreglea, A.; Liu, F.; Foley, A. A dynamic analysis of energy storage with renewable and diesel generation using Volterra equations. IEEE Trans. Ind. Inform. 2019, 16, 3451-3459. [CrossRef]

36. Ahmadi, S.; Arabani, H.P.; Haghighi, D.A.; Guerrero, J.M.; Ashgevari, Y.; Akbarimajd, A. Optimal use of vehicle-to-grid technology to modify the load profile of the distribution system. J. Energy Storage 2020, 31, 101627. [CrossRef]

37. Bandyopadhyay, S.; Mouli, G.R.C.; Qin, Z.; Elizondo, L.R.; Bauer, P. Techno-economical model based optimal sizing of PV-battery systems for microgrids. IEEE Trans. Sustain. Energy 2019, 11, 1657-1668. [CrossRef]

38. Crow, M.L. Electric vehicle scheduling considering co-optimized customer and system objectives. IEEE Trans. Sustain. Energy 2017, 9, 410-419.

39. Javidsharifi, M.; Niknam, T.; Aghaei, J.; Mokryani, G.; Papadopoulos, P. Multi-objective day-ahead scheduling of microgrids using modified grey wolf optimizer algorithm. J. Intell. Fuzzy Syst. 2019, 36, 2857-2870. [CrossRef]

40. Bartolucci, L.; Cordiner, S.; Mulone, V.; Pasquale, S. Fuel cell based hybrid renewable energy systems for off-grid telecom stations: Data analysis and system optimization. Appl. Energy 2019, 252, 113386. [CrossRef]

41. Javidsharifi, M.; Niknam, T.; Aghaei, J.; Mokryani, G. Multi-objective short-term scheduling of a renewable-based microgrid in the presence of tidal resources and storage devices. Appl. Energy 2018, 216, 367-381. [CrossRef]

42. Narimani, M.R.; Vahed, A.A.; Azizipanah-Abarghooee, R.; Javidsharifi, M. Enhanced gravitational search algorithm for multiobjective distribution feeder reconfiguration considering reliability, loss and operational cost. IET Gener. Transm. Distrib. 2014, 8, 55-69. [CrossRef]

43. Rao, R. Jaya: A simple and new optimization algorithm for solving constrained and unconstrained optimization problems. Int. J. Ind. Eng. Comput. 2016, 7, 19-34.

44. Javidsharifi, M.; Niknam, T.; Aghaei, J.; Shafie-khah, M.; Catalão, J.P. Probabilistic Model for Microgrids Optimal Energy Management Considering AC Network Constraints. EEE Syst. J. 2019, 14, 2703-2712. [CrossRef]

45. Mahboubi-Moghaddam, E.; Narimani, M.R.; Khooban, M.H.; Azizivahed, A.; Sharifi, M. Multi-objective distribution feeder reconfiguration to improve transient stability, and minimize power loss and operation cost using an enhanced evolutionary algorithm at the presence of distributed generations. Int. J. Electr. Power Energy Syst. 2016, 76, 35-43. [CrossRef] 